\title{
The Spatiotemporal Evolution
}

\section{of U.S. Carbon Dioxide Emissions:}

\section{Stylized Facts and Implications for Climate Policy}

\author{
James G. Baldwin* \\ Visiting Assistant Professor \\ Dept. of Earth \& Environment \\ Boston University
}

\author{
Ian Sue Wing
}

Associate Professor

Dept. of Earth \& Environment

Boston University

This draft: September 2012

\begin{abstract}
We characterize the evolution of U.S. carbon dioxide $\left(\mathrm{CO}_{2}\right)$ emissions using an index number decomposition technique which partitions the 1963-2008 growth of states' energy-related $\mathrm{CO}_{2}$ into changes in five driving factors: the emission intensity of energy use, the energy intensity of economic activity, the composition of states' output, per capita income and population. Compositional change and declining energy intensity attenuate emissions growth, but their impacts are offset by increasing population and income. Despite absolute interstate divergence in both emissions and their precursors, states' emission- and energy intensities-and, ultimately, $\mathrm{CO}_{2}$-appear to be stochastically converging. We assess the implications of these trends using a novel vector autoregression (VAR) emission forecasting technique based on our index numbers. The resulting emission projections are comparable to, but generally exceed, those forecast by the 2010 EIA Annual Energy Outlook.
\end{abstract}

JEL categories: R10, Q47, Q53

*Address: 675 Commonwealth Ave., Boston, MA 02215. Tel.: +1 (617) 353-2525. Email: jbaldwin@bu . edu. 


\section{Introduction}

Recent developments in U.S. climate change policy have seen the first tentative steps toward legislating a binding aggregate emission cap and implementing curbs on GHGs at the state and regional levels. ${ }^{1}$ This state and regional level policy action has been identified as both a critical element in U.S. emissions reductions and as a force to shape national climate change mitigation policy (Lutsey and Sperling, 2008; Byrne et al., 2007; Rabe, 2008). Consequently the resulting economic effects of these policies is the subject of intense recent interest (Grainger and Kolstad, 2009; Hassett et al., 2009; Sue Wing, 2010). The first step in making any such assessment, and one incorporated or mandated in all state climate action plans (EPA, 2012), is to forecast how states' baseline emissions are likely to evolve. Prerequisite to such projections is the ability to characterize the geographic variations in the precursors of GHGs-particularly $\mathrm{CO}_{2}$-based on an understanding of their historical evolution.

In this paper we investigate how the driving forces behind U.S. carbon dioxide emissions have evolved over the period 1963-2008. We take an explicitly spatial approach, quantifying in detail the interregional variations in $\mathrm{CO}_{2}$ precursors that are largely absent in the literature. While several recent papers have exploited state-level databases on the prices and quantities of fuel use, their focus has been quantifying the aggregate effects of drivers such as income and prices. ${ }^{2}$ The unfortunate consequence is that the substantial interregional heterogeneity underlying these results, which is interesting in its own right, has largely been ignored. An important exception to this general trend is Metcalf's (2008) inquiry into the drivers of the energy intensity of U.S. states, which he disaggregates into intra-sectoral changes in energy efficiency and inter-sectoral changes in the structure of economic activity. This paper's key feature is the use of index number decomposition analysis, which is a popular technique for apportioning the time-evolution of a composite

\footnotetext{
${ }^{1}$ The Regional Greenhouse Gas Initiative limits $\mathrm{CO}_{2}$ emissions from electricity generation in ten New England and Mid-Atlantic states from 2009 onward, while California's Global Warming Solutions Act of 2006 caps that state's GHG emissions in 2020 to a target of 427 million tons of $\mathrm{CO}_{2}$-equivalents, and the American Clean Energy and Security Act of 2009 implements an economy-wide cap-and-trade scheme for cutting US GHGs to 83 \% of their 2005 levels by 2050. In total 32 states currently have climate action plans to develop mitigation strategies (EPA, 2012)

${ }^{2}$ Aldy (2005) performs a test of the environmental Kuznets curve by examining the dependence of emissions on states' per capita incomes, while Aldy (2007a) and Aldy (2007b) investigate the relationships between energy and income and emissions and income at the state level and their variation across industries and shed light on the lack of convergence in state-level per capita emissions. Finally, Auffhammer and Steinhauser $(2007,2010)$ exploit the interstate co-variation of income and emissions to improve forecasts of aggregate $\mathrm{CO}_{2}$.
} 
variable into contributions associated with movements in its constituent factors. ${ }^{3}$ We build on this approach, developing an extended decomposition framework which attributes the evolution of $\mathrm{CO}_{2}$ emissions over space and time to five precursors: the emissions intensity of energy use, the energy intensity of economic activity, the composition of states' output, per capita income and population.

This rest of the paper is structured as follows. In section 2 we develop our decomposition framework and give a brief overview of our sources of data. Our findings are presented and discussed in section 3, which summarizes our five drivers at the national, regional and state levels and tests whether the pattern of their evolution is consistent with interstate convergence. Finally we present a forecast of emissions utilizing the decomposition model output 4 . Section 5 concludes.

\section{Decomposition Methodology and Data}

The starting point for our analysis is the familiar Kaya Identity (Kaya, 1990), which expresses $\mathrm{CO}_{2}$ emissions as the product of the emission intensity of energy use, the energy intensity of income, GDP per capita and the level of population. We extend this framework to take full advantage of the availability of U.S. data on energy use by $f$ types of fuel in $j$ economic sectors, $s$ states, and $t \in[0, T]$ time periods. Our approach is particularly simple. In any year, the aggregate emissions of a sample of $S$ states, $\mathscr{C}$, are given by the sum over sectors and states of disaggregate emissions, $\chi$. In turn, this quantity the sum over fuel types of disaggregate fuel use, indicated by $\varepsilon$, multiplied by a fuel-specific emission coefficient, $\vartheta$ :

$$
\mathscr{C}_{t}=\sum_{s \in S} \sum_{j} \chi_{j, s, t}=\sum_{s \in S} \sum_{j} \sum_{f}\left(\vartheta_{f} \varepsilon_{f, j, s, t}\right)
$$

Let $e$ denote a particular industry's energy use in a given state and year $\left(e_{j, s, t}=\sum_{f} \varepsilon_{f, j, s, t}\right)$, and let $y$ indicate that industry's value-added in constant dollars. Then, using $Y$ to indicate the state's real GDP $\left(Y_{s, t}=\sum_{j} y_{j, s, t}\right)$, and $N$ to denote its population, we may write down an extended Kaya

\footnotetext{
${ }^{3}$ See Ang and Zhang (2000) for an extensive review. Since this, survey decomposition methods have, if anything, become more popular, but the overwhelming majority of such studies are cross-country comparisons (see, variously, Lee and Oh, 2006; Kawase et al., 2006; Ebohon and Ikeme, 2006; Lu et al., 2007; Diakoulaki and Mandaraka, 2007; Raupach et al., 2007).
} 
identity:

$$
\chi_{j, s, t}=\underbrace{\frac{\chi_{j, s, t}}{e_{j, s, t}}}_{\xi} \times \underbrace{\frac{e_{j, s, t}}{y_{j, s, t}}}_{\phi} \times \underbrace{\frac{y_{j, s, t}}{Y_{s, t}}}_{\theta} \times \underbrace{\frac{Y_{s, t}}{N_{s, t}}}_{I} \times N_{s, t} .
$$

The right-hand side of this expression attributes emissions to five key driving forces: from left to right, the $\mathrm{CO}_{2}$ intensity of fuel use $(\xi)$, energy intensity of output $(\phi)$ and fraction of state value added $(\theta)$ of industries within states, followed by states' per capita income $(I)$ and population. Note that the product of the first two terms is just the emission intensity of each sector within a given state, while the sum over industries of the product of all three industry-level terms is just the particular state's $\mathrm{CO}_{2}$-GDP ratio, which we denote $X\left(X_{s, t}=\sum_{j} \xi_{j, s, t} \phi_{j, s, t} \theta_{j, s, t}\right)$. Exploiting this fact, we combine (1) and (2) to obtain a simple expression for aggregate emissions:

$$
\mathscr{C}_{t}=\sum_{s \in S} X_{s, t} I_{S, t} N_{s, t}
$$

Obviously, the term within the summation sign represents each state's emissions, which we indicate using $C$.

Our decomposition procedure attributes the change in aggregate emissions to changes in the five drivers in the following way. We model the instantaneous growth rate of $\mathscr{C}$ by taking the logarithmic differential of (3). After rearrangement, this procedure yields:

$$
\frac{\partial}{\partial t} \log \mathscr{C}_{t}=\underbrace{\sum_{s \in S} \omega_{s, t} \frac{\partial}{\partial t} \log X_{s, t}}_{\sum_{s} \mathscr{X}_{s, t}}+\underbrace{\sum_{s \in S} \omega_{s, t} \frac{\partial}{\partial t} \log I_{s, t}}_{\sum_{a} \mathscr{I}_{s, t}}+\underbrace{\sum_{s \in S} \omega_{s, t} \frac{\partial}{\partial t} \log N_{s, t}}_{\sum_{s} \mathscr{N}_{s, t}}
$$

where $\omega$ is a time-varying weight that corresponds to the contribution of each state to total emissions $\left(\omega_{s, t}=C_{s, t} / \mathscr{C}_{t}\right)$. Applying the same procedure to the $\mathrm{CO}_{2}$ intensity of GDP allows us to express the rate of growth of this quantity as the weighted sum of the logarithmic differentials of the three industry-level factors:

$$
\frac{\partial}{\partial t} \log X_{s, t}=\sum_{j} \eta_{j, s, t} \frac{\partial}{\partial t} \log \xi_{j, s, t}+\sum_{j} \eta_{j, s, t} \frac{\partial}{\partial t} \log \phi_{j, s, t}+\sum_{j} \eta_{j, s, t} \frac{\partial}{\partial t} \log \theta_{j, s, t}
$$

where the weight $\eta_{j, s, t}$ varies over time and states, and represents each sector's contribution to the emission intensity of the state in which it is situated $\left(\eta_{j, s, t}=\xi_{j, s, t} \phi_{j, s, t} \theta_{j, s, t} / X_{s, t}\right)$. Consequently, the 
first right-hand-side term in (4) can be expanded as:

$$
\mathscr{X}_{s, t}=\underbrace{\omega_{s, t}\left[\sum_{j} \eta_{j, s, t} \frac{\partial}{\partial t} \log \xi_{j, s, t}\right]}_{\Xi_{s, t}}+\underbrace{\omega_{s, t}\left[\sum_{j} \eta_{j, s, t} \frac{\partial}{\partial t} \log \phi_{j, s, t}\right]}_{\Phi_{s, t}}+\underbrace{\omega_{s, t}\left[\sum_{j} \eta_{j, s, t} \frac{\partial}{\partial t} \log \theta_{j, s, t}\right]}_{\Theta_{s, t}}
$$

Eqs. (4) and (5) decompose the annual rates of change of states' emissions into five timevarying factors $\left(\mathbf{Z}_{s, t}=\left[\Xi_{s, t}, \Phi_{s, t}, \Theta_{s, t}, \mathscr{I}_{s, t}, \mathscr{N}_{s, t}\right]^{\prime}\right)$ which attribute observed growth and decline to the effects of the corresponding drivers. The empirical implementation of this procedure is a straightforward calculation in which the log-derivatives are approximated as centered-difference growth rates: $\partial \log \mathbf{Z} / \partial t \approx 2\left(\mathbf{Z}_{t}-\mathbf{Z}_{t-1}\right) /\left(\mathbf{Z}_{t}+\mathbf{Z}_{t-1}\right)$, and the weights are computed as the averages of the state and sectoral shares of aggregate emissions in adjacent periods. ${ }^{4}$ We compute the cumulative impacts of the various factors relative to the initial year by chaining the sequence of annual growth rates for each factor across years starting from a value of unity in $1963(t=0)$. The result is a vector of index numbers, which we henceforth identify using a tilde: $\widetilde{\mathbf{Z}}_{s, t}=\left[\widetilde{\Xi}_{s, t}, \widetilde{\Phi}_{s, t}, \widetilde{\Theta}_{s, t}, \widetilde{\mathscr{I}}_{s, t}, \widetilde{\mathscr{N}}_{s, t}\right]^{\prime}:$

$$
\widetilde{\mathbf{Z}}_{s, t}=\prod_{\tau=1}^{t}\left(\frac{2+\mathbf{Z}_{s, \tau}}{2-\mathbf{Z}_{s, \tau}}\right) .
$$

It is worth emphasizing that these are composite variables which embody not only the fundamental trend in the variable in question (e.g., the rate of change in a state's energy-output ratio) but also the extent to which that trend contributes to aggregate emissions. We shall see in Section 4 that this property proves very useful in constructing emission projections at the state level.

In this regard, a key benefit of our decomposition technique is the ability to express our index numbers in terms of $\mathrm{CO}_{2}$ emission equivalents. Let our five drivers be denoted by the in$\operatorname{dex} i$, which we use to identify the elements of $\mathbf{Z}_{s, t}$. The instantaneous growth rate of statelevel emissions is therefore $G_{s, t}=\sum_{i} Z_{s, t}^{i}$, which, as in (6), can be approximated as $\Delta \log C_{s, t} \approx$

\footnotetext{
${ }^{4}$ Our method is functionally equivalent to the Arithmetic Mean Divisia index number decomposition (Ang, 2002, 2005; Ang and Liu, 2001), while having the advantages of a small residual and the ability to gracefully handle negative values and isolated zeros on both sides of the decomposition equation (cf. Ang and Liu, 2007). Boyd and Roop (2004) and especially Metcalf (2008) advocate for the use of a Fisher ideal index because of its superlative theoretical properties and zero residual. However, using the Fisher index number approach to decompose an aggregate series into numerous factors quickly results in intractably complex mathematical formulae (see, e.g., Ang et al., 2004)—particularly in cases such as our application where there are multiple summations, and in any case despite the use of discrete approximations of the logarithmic differential and interperiod linear instead of log mean weights, the fit of our simpler decomposition to the data is excellent. The residual from the decomposition has magnitude less than $0.5 \%$ of the trend in aggregate emissions.
} 
$2\left(C_{s, t}-C_{s, t-1}\right) /\left(C_{s, t}+C_{s, t-1}\right)$. We may therefore write the inter-period change in the level of a state's emissions as $\Delta C_{s, t}=C_{s, t}-C_{s, t-1} \approx 0.5\left(C_{s, t}+C_{s, t-1}\right) \sum_{i} Z_{s, t}^{i}$, which our procedure above disaggregates into components attributable to each factor $\delta_{s, t}^{i}=0.5\left(C_{s, t}+C_{s, t-1}\right) Z_{s, t}^{i}$. Cumulating each component over time yields the analogue of our chained index numbers, expressed in units of emissions:

$$
D_{s, t}^{i}=\sum_{\tau=0}^{t} \delta_{s, \tau}^{i} .
$$

Data on energy use by fuel, sector and state for the period 1963-2008, average $\mathrm{CO}_{2}$ emission factors, and state $\mathrm{CO}_{2}$ emissions were calculated using energy consumption data taken from the U.S. Energy Information Administration's (EIA) State Energy Data System (SEDS). We obtained state-level time series of population and nominal value added by detailed industry groupings for the same period from the Bureau of Economic Analysis regional accounts. The latter were aggregated to match the EIA sectoral groupings and converted to real values using the GDP deflator from the NIPAs. ${ }^{5}$

\section{Stylized Facts}

\subsection{Aggregate and Regional Trends}

The results of (7) are shown in Figure 1. Aggregate emissions doubled over the study period growing by just under $3 \mathrm{Gt}$ prior to the recession. This increase was driven primarily by the growth of per capita income, whose impact contributed nearly 5 Gt of added emissions potential, and, to a lesser extent, population, whose impact increased by just over $2 \mathrm{Gt}$. The emissions reducing influence of energy's emission intensity is modest by comparison at less than $1.4 \mathrm{Gt}$, while energy intensity and structural change are more potent inhibiting factors, reducing emissions by 1.8 and $1.5 \mathrm{Gt}$, respectively, below 1963 levels. These trends indicate that in the absence of these offsetting impacts US emissions in 2008 would be nearly double their actual level of 5.8 GT, resulting in cumulative emissions over the sample period that are some 55\% higher than the actual stock of 215 Gt (cf Metcalf, 2008). The fact that cumulative emissions are 3.2 Gt higher absent either emission-

\footnotetext{
${ }^{5}$ The switch in BEA's tabulation of industry groupings from the Standard Industrial Classification (SIC) to the North American Industry Classification System (NAICS) posed a particular problem. The two series were concatenated by aggregating separately from SIC and NAICS to EIA sectors, and then making adjustments to the NAICS series based on the ratio of SIC to NAICS values for the 1997 base year when the series overlap.
} 
or energy intensity, and 4.7 Gt higher without structural change, highlights the importance of fuel switching, energy-saving technological progress and particularly compositional shifts in moderating emissions over the long run (cf Sue Wing, 2008).

Turning to the regional level, the patterns of evolution of $\mathrm{CO}_{2}$ emissions and its five precursors is broadly similar in character, but of variable magnitude. The Northeast is the only region where emissions appear to be stabilizing, while their growth is faster but still modest in the Midwest, and rapid in the West and especially the South. In all regions there are large and positive impacts associated with per capita income, coupled with the emissions reducing impacts of energy intensity, structural change and the $\mathrm{CO}_{2}$-intensity of energy use.

The direct impact of state or regional emissions targets is not evident in our results as the earliest adoption of such a plan did not occur until Rhode Island's emissions target setting in 2002 and the majority of the remaining plans not being implemented until 2007 or later (EPA, 2012). But an interesting observation in these results is the apparent influence of the Clean Air Act (CAA) in 1970, and its amendments in 1977 and 1990, as indicated by the dashed lines in Figure 1. At all geographic scales total emissions growth deflects downward slightly after these dates. At the aggregate level this deflection is due to a decline in energy intensity related emissions in 1970 and 1990, and a small decline in structural change related emissions in 1977. Though very modest, similar deflections in the trend are seen at the regional level with some variation in the exact mechanism of influence on total emissions.

Far more striking emissions declines follow the 1973 and 1979 oil price shocks indicated by solid lines in Figure 1. During the crises the price of crude oil increased dramatically from $\$ 21.07$ per barrel to $\$ 58.23$ in real terms from 1973 to 1974 , and $\$ 68.15$ to $\$ 94.24$ between 1979 and 1980 (EIA, 2012). Both events signal marked declines in overall emissions growth that lasted two years after the 1973 crisis and four years after the 1979 crisis, reducing emissions by 0.3Gt and 0.6Gt respectively. In the first instance the primary mechanism for the decline is a drop in per capita income as rising energy costs drove down consumer spending and economic output (Edelstein and Kilian, 2009). The 1979 decline is driven by a fall in energy intensity related emissions with little or no influence from changes in income, a pattern seen across all regions. Following the collapse of crude oil prices in the early 1980s, when oil prices fell from over $\$ 90$ to less than $\$ 30$ in real terms (EIA, 2012), emissions begin steady growth, achieving pre-1979 crisis levels by 1988. The 


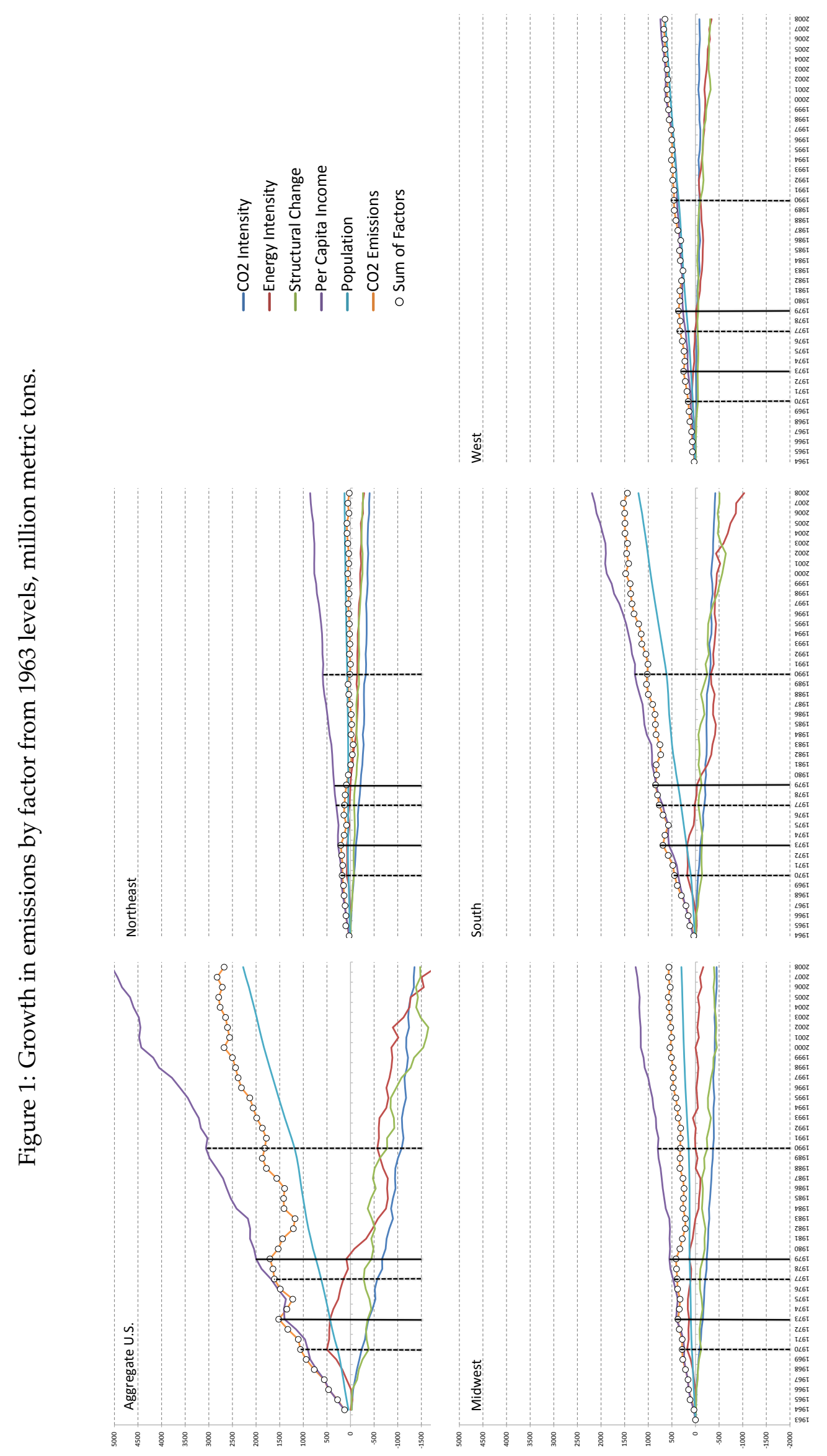


economic impact of oil price shocks is widely discussed in the energy literature, ${ }^{6}$ and a detailed discussion of this finding is outside the scope of this paper. However, our analysis provides some insight into the response to these price disturbances and shows an economy better able to adapt to rising oil prices following the 1973 crisis.

\subsection{State-Level Trends}

Underlying the national results is a great deal of heterogeneity at the state level, which our decomposition approach makes it possible to characterize. For ease of exposition we examine the cumulative growth in the emissions contributed by our five drivers over two time periods, 19631985 and 1986-2008, which we summarize as a series of maps in Figure 2.

Panels A and B illustrate the growth of $\mathrm{CO}_{2}$ emissions at the state level. Panels $\mathrm{C}$ and D show the effect of emission intensity, which is more variable at the state than at the regional level. Panels $\mathrm{E}$ and $\mathrm{F}$ show the effect of energy intensity, which is generally large and exhibits considerable heterogeneity, reflecting the geographic variation in energy saving technological change. In the first period energy intensity change exerts downward pressure on emissions in almost every state. In the second period there is a fourfold increase in the number of states in which energy intensity has an amplifying effect on emissions.

Panels G and H illustrate how structural change has slowly but steadily acted to reduce aggregate emissions. Exceptions to this trend are Alaska's expansion in the first period, followed closely by the coal states of Wyoming and North Dakota. In the second period Alaska, Wyoming and North Dakota experience declines and a handful of formerly negative states begin to see their emissions grow via this path.

The growth in emissions due to rising income in panels I and J is uniformly positive throughout the sample period. Panels K and L show the influence of population, which has the most clearly delineated spatial pattern in both time periods, and whose magnitude is second only to per capita income growth as a contributor to emissions. Throughout the duration of the dataset this effect is unsurprisingly largest in California, Texas and Florida.

\footnotetext{
${ }^{6}$ See Hamilton (1983); Burbidge and Harrison (1984); Mork (1989); Bohi (1991); Mork et al. (1994); Hamilton (2003); Jimenez-Rodriguez and Sanchez (2005); Blanchard and Gali (2007)
} 
Figure 2: Cumulative Increase in State-Level $\mathrm{CO}_{2}$ Attributable to Emissions Precursors (MT)

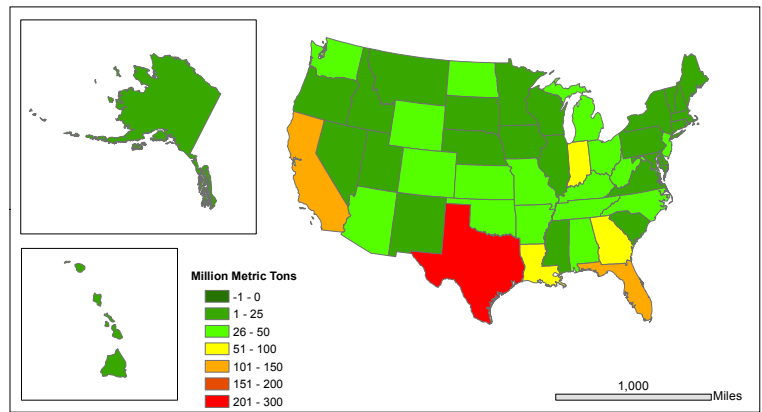

A. $\mathrm{CO}_{2}$ emissions $(\widetilde{C}), 1963-1985$

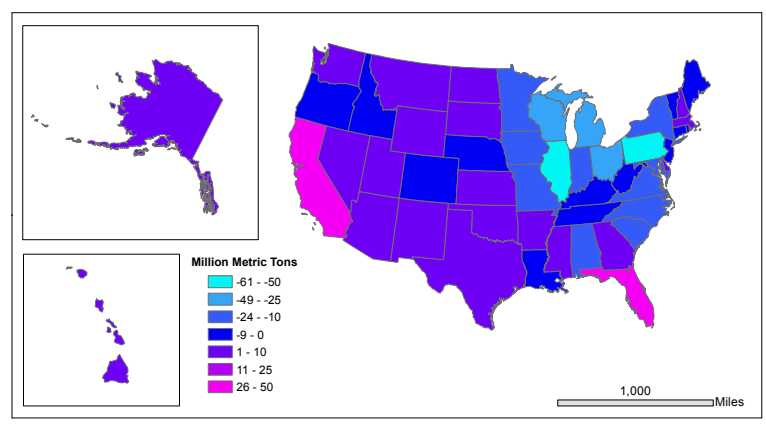

C. $\mathrm{CO}_{2}$ intensity $(\widetilde{\Xi}), 1963-1985$

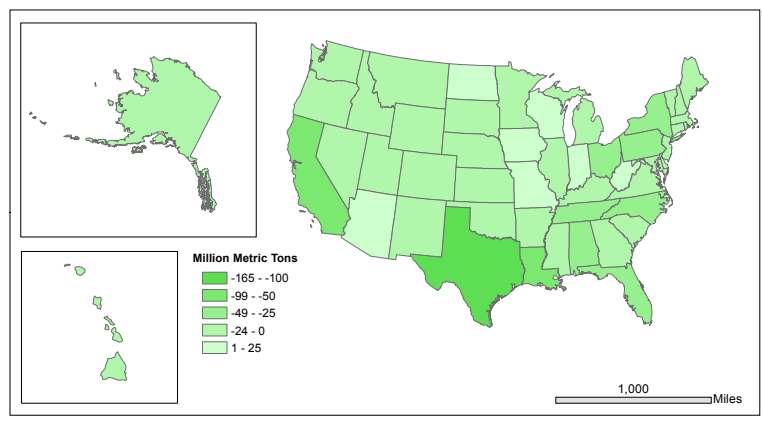

E. Energy intensity $(\widetilde{\Phi}), 1963-1985$

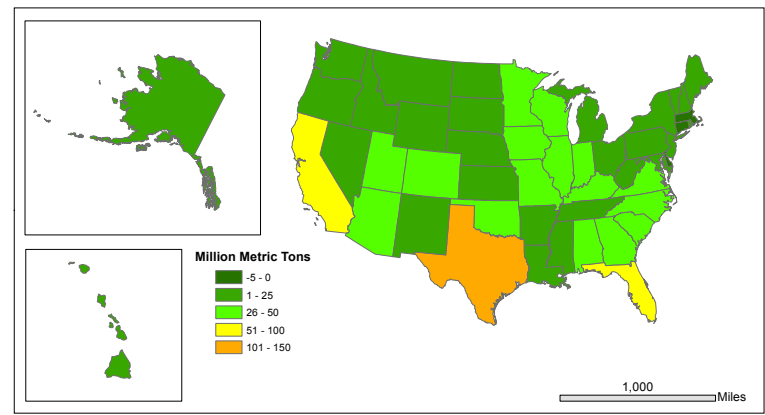

B. $\mathrm{CO}_{2}$ emissions $(\widetilde{C}), 1986-2008$

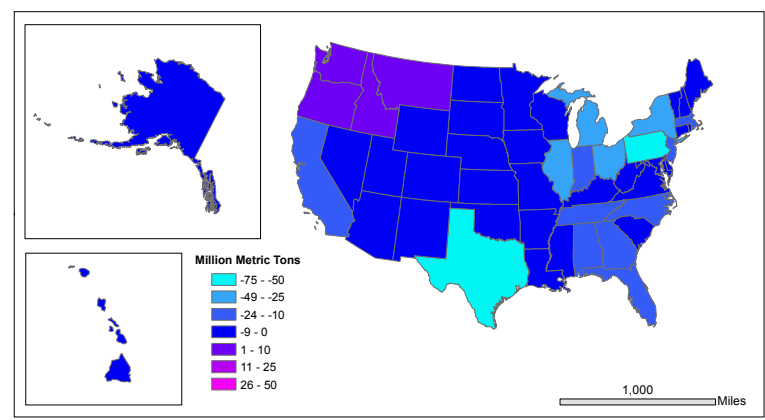

D. $\mathrm{CO}_{2}$ intensity $(\widetilde{\Xi}), 1986-2008$

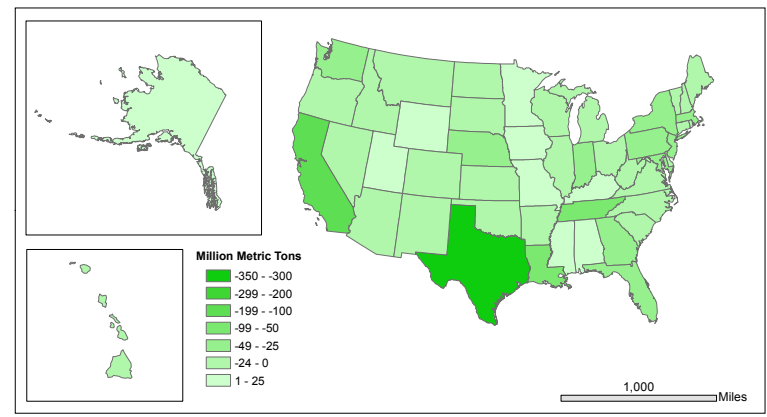

F. Energy intensity $(\widetilde{\Phi}), 1986-2008$ 
Figure 2: Cumulative Increase in State-Level $\mathrm{CO}_{2}$ Attributable to Emissions Precursors (MT)continued

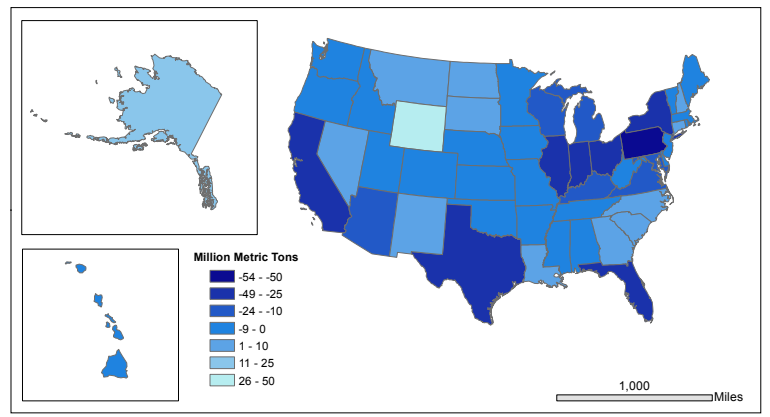

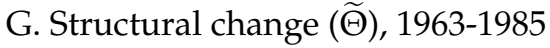

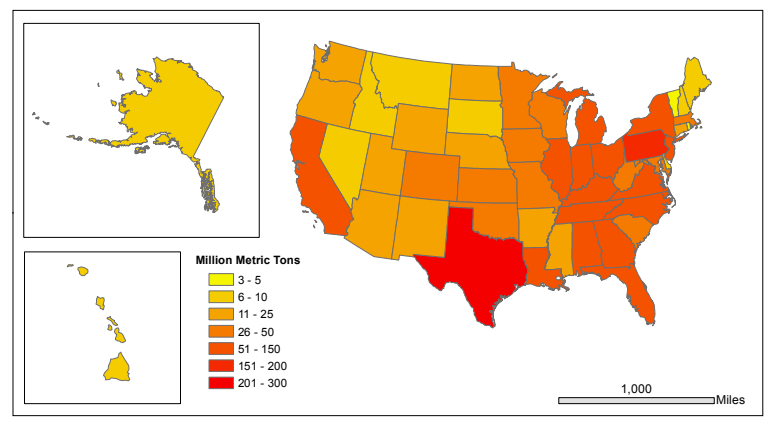

I. Per capita income $(\widetilde{\mathscr{I}}), 1963-1985$

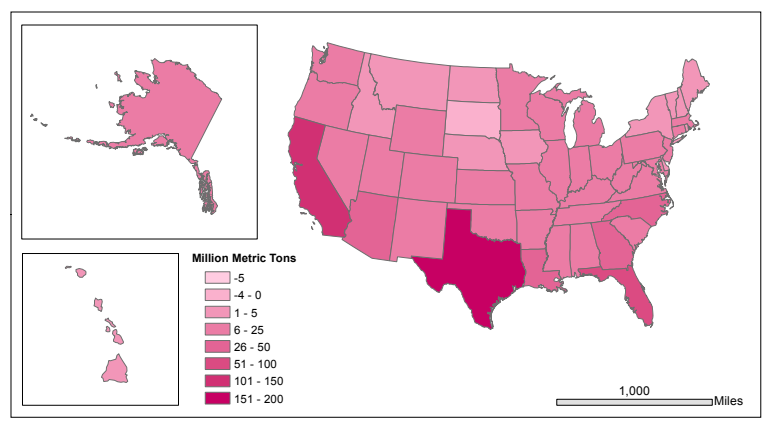

K. Population $(\widetilde{\mathscr{N}}), 1963-1985$

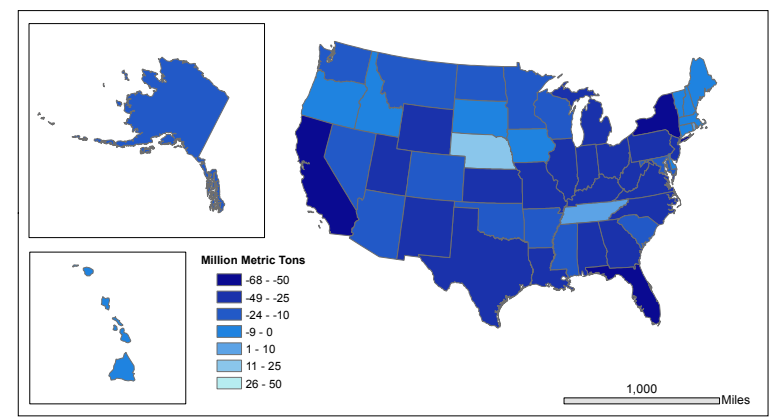

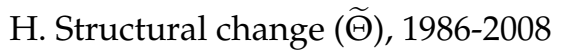

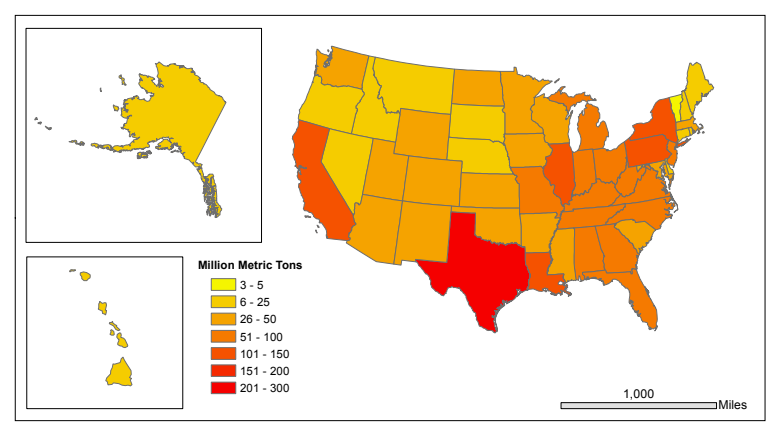

J. Per capita income $(\widetilde{\mathscr{I}}), 1986-2008$

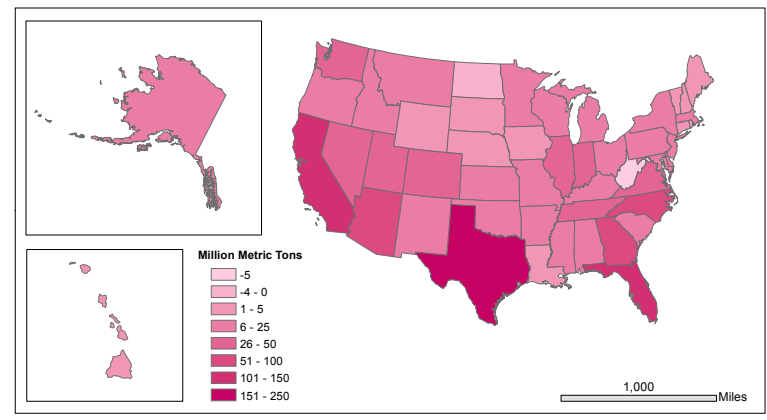

L. Population $(\widetilde{\mathscr{N}}), 1986-2008$ 


\subsection{Interstate Convergence of Growth in Emissions and Their Precursors}

Given the foregoing results it is useful to ask whether states' contributions to emissions along the five dimensions are becoming more or less similar over time. Answering this question yields fresh insights into the underpinnings of Aldy's (2007b) finding of interstate divergence in per capita emissions.

To more rigorously characterize the implications of these patterns, we employ the methods used by List (1999), Strazicich and List (2003) and Aldy (2007b) to test for convergence among state per capita emissions. We first test for "absolute" or $\sigma$-convergence (Barro and Sala-i Martin, 1992) by examining whether the dispersion of each factor across states is decreasing over time. Our statistic of choice is the coefficient of variation (CV), which in each period expresses the interstate variance of each factor as a fraction of the mean of all states. The result is that states $\sigma$-diverge along every dimension. Figure 3A shows that the interstate dispersion of the indexes of per capita income's influence increase only slightly, while population's effect continually and strongly diverges throughout the sample period. The dispersion of the remaining precursor indexes continues to increase post-1985, but at a markedly slower rate, while the CV of structural change effect exhibits non-monotonic behavior, rising slowly at first before jumping upward in the wake of the OPEC oil price shocks, fluctuating and then declining into the 1990s before slowly rising once more.

Next, we examine the stochastic convergence of the factors of emissions. In contrast to the familiar cross-sectional concept of $\beta$-convergence, stochastic convergence is a time-series concept in which economies are said to have converged if the disparities between them follow a zero mean stationary process, which is more appropriate for the analysis of index numbers of the type we construct here. ${ }^{7}$ The practical elaboration of this condition is that the logarithm of the ratio of a particular factor at the state level to the U.S. mean is stationary. We test each of our factors for this

\footnotetext{
${ }^{7}$ With $\beta$-convergence, economies which start out with high values of a particular factor will tend to grow relatively slowly, while those with low values at the beginning of the sample period will tend grow relatively quickly, and as a result exhibit "catch-up" behavior. If economies are identical in terms of the attributes that determine the factor in question, so that all possess the same steady state, then we should see "absolute" or "unconditional" $\beta$-convergence, which is a necessary condition for $\sigma$-convergence. A more likely situation is "conditional" $\beta$-convergence, where economies possess different steady states and therefore converge to different equilibrium levels of the factor, but, conditional on one or more attributes being the same across economies, absolute convergence would be attained. The difficulty that arises in applying these concepts to our index number series is that the latter are constructed to have the same base of unity, which makes the assessment of catch-up problematic. Tests for stochastic convergence thus provide a convenient means to circumvent this problem.
} 
Figure 3: Convergence in $\mathrm{CO}_{2}$ Emissions and Precursors

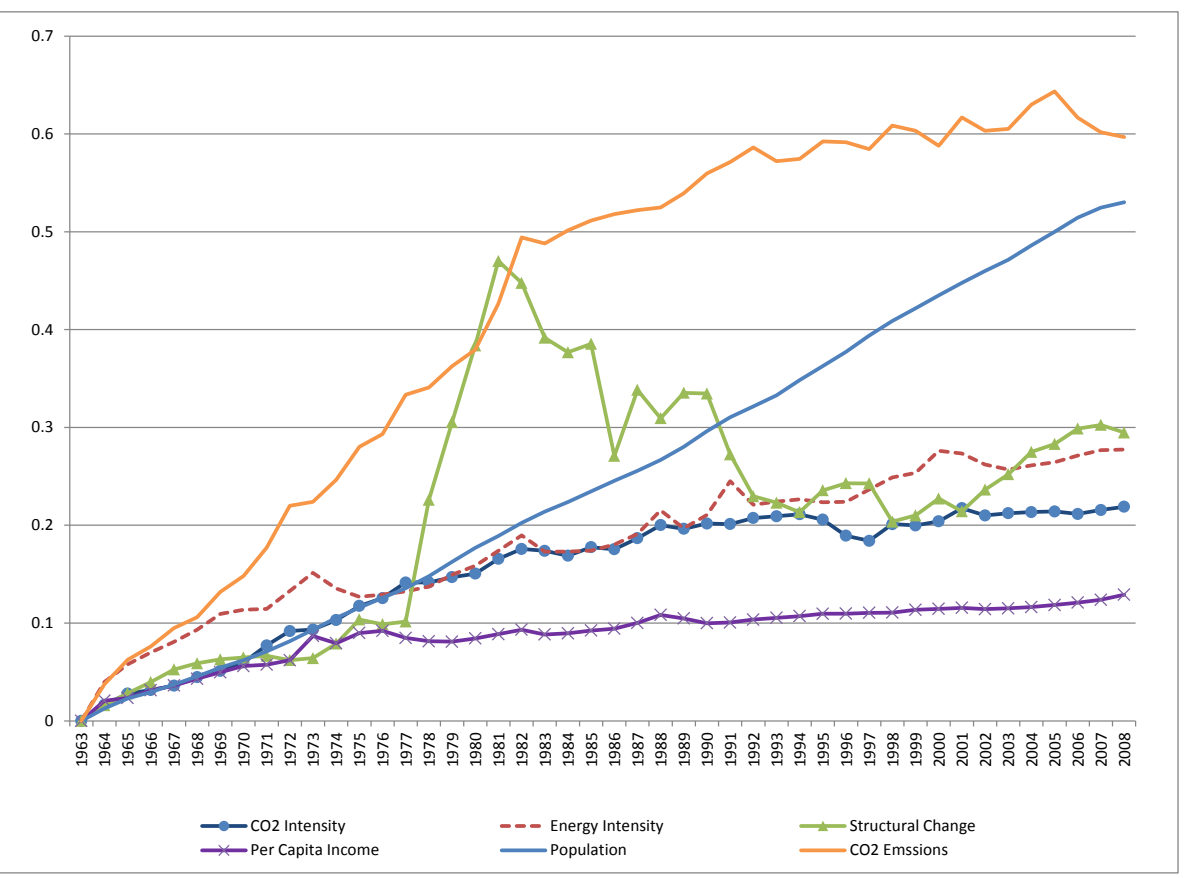

A. $\sigma$-Divergence: Coefficients of Variation of Indexes of Emissions and Precursors

\begin{tabular}{lll}
\hline & \multicolumn{2}{c}{$\bar{t}$ statistic } \\
Variable & $1963-2008$ & $1986-2008$ \\
\hline Emission Intensity $(\log$ relative $\widetilde{\Xi})$ & $-1.893^{* *}$ & $-2.485^{* * *}$ \\
Energy Intensity $(\log$ relative $\widetilde{\Phi})$ & -1.633 & $-1.898^{* * *}$ \\
Structural Change $(\log$ relative $\widetilde{\Theta})$ & -1.576 & $-1.734^{* * *}$ \\
Per Capita Income $(\log$ relative $\widetilde{\mathscr{I}})$ & -1.615 & -1.093 \\
Population $(\log$ relative $\widetilde{\mathscr{N}})$ & -0.371 & -0.853 \\
$\mathrm{CO}_{2}$ Emissions $(\log$ relative $\widetilde{C})$ & $-1.745^{* * *}$ & $-2.042^{* * *}$ \\
\hline
\end{tabular}

Critical values: ${ }^{*} 10 \%-1.64,{ }^{* *} 5 \%-1.67,{ }^{* * *} 1 \%-1.73$.

B. Stochastic Convergence: Im, Pesaran and Shin Test of Log Indexes 
using the statistical procedure developed by Im et al. (2003), which is a test of the null hypothesis that the series has a unit root (for details, see Strazicich and List, 2003).

Our results in Figure 3B are an important qualification of Aldy's findings. Interestingly, over the period 1963-2008 the null is decisively rejected for the contributions of $\mathrm{CO}_{2}$ intensity and for overall emissions. Simultaneously, however, states are becoming less similar in terms of the contributions to emissions of energy intensity, compositional change, affluence and population. Split sample tests provide statistical confirmation of the apparent saturation in our index numbers' CVs in the post-1985 period. The corresponding $\bar{t}$ statistics attest to the stronger influences of $\mathrm{CO}_{2}$ intensity, energy intensity and, in this more recent period, the impact structural change on the convergence of the trends in states' emissions. These results suggest that Aldy's finding of interstate divergence in per capita emissions is due to divergence in the growth of states' populations and, to a lesser extent, per capita incomes, whose effects outweigh convergence in the growth of the remaining precursors, and ultimately emissions themselves.

The implications for future aggregate emissions and their regional distribution are not immediately clear. Establishing what the likely patterns are in that regard is the question to which we now turn.

\section{Future Aggregate and Regional $\mathrm{CO}_{2}$ Emissions}

We utilize the large amount of data generated by our decomposition analysis to construct a 27year forecast of $\mathrm{CO}_{2}$ emissions. Instead of estimating the average covariation between income and emissions across all states, as Auffhammer and Steinhauser $(2007,2010)$ do, we exploit the joint covariation among all of the emission precursors in each state, generating 51 independent state-level projections which we then combine to produce an aggregate emissions forecast. Our approach is to econometrically estimate the covariance among factors by running the following vector autoregression (VAR):

$$
\log \widetilde{\mathbf{Z}}_{s, t}=\mathscr{A}_{S}+\sum_{\ell=1}^{L} \mathscr{B}_{s, \ell} \log \widetilde{\mathbf{Z}}_{s, t-\ell}+\mathbf{u}_{s, t}
$$

where $\mathscr{A}$ and $\mathscr{B}$ are $5 \times 1$ and $5 \times 5 \times \ell$ matrices of parameters to be estimated, and our default 
lag-length is set at $L=2$ to conserve degrees of freedom. Following the logic of our discussion in Section 2, the projected values of each index number embody both the fundamental time-trend in the underlying variable and its contribution to the trend in aggregate emissions. This obviates the inclusion of spatial lags of the covariates, allowing each state VAR to be run independently of the others. The fundamental advantage of our VAR approach is that it is entirely self-contained, with no need to rely on exogenous projections of the future growth of population and GDP (cf Auffhammer and Steinhauser, 2010) or emission- and energy intensity (Yang and Schneider, 1998).

Running the regression (8) in logarithms constrains the forecast values of the emission precursors $\left(\widetilde{\mathbf{Z}}^{\star}\right)$ to be strictly positive, while allowing them to be readily converted into total $\mathrm{CO}_{2}$ emissions by running our decomposition algorithm in reverse. In particular, eqs. (4)-(5) imply that in forecast year $T+k$ the growth rate of emissions at the state level is given by

$$
\begin{aligned}
G_{s, T+k}^{\star}=\Delta \log \widetilde{C}_{s, T+k}^{\star}=\Delta \log \widetilde{\Xi}_{s, T+k}^{\star}+\Delta \log \widetilde{\Phi}_{s, T+k}^{\star}+\Delta \log \widetilde{\Theta}_{s, T+k}^{\star} & \\
& +\Delta \log \widetilde{\mathscr{I}}_{s, T+k}^{\star}+\Delta \log \widetilde{\mathscr{N}}_{s, T+k}^{\star}
\end{aligned}
$$

which allows us to project the levels of states' future $\mathrm{CO}_{2}, \mathrm{C}_{s, T+k}^{\star}$, by chaining together the sum of the first-differenced logarithms of the forecast values of their emission precursors, starting with last year in which emissions are observed $(T=2008)$. Following eq. (6):

$$
C_{s, T+k}^{\star}=\prod_{\tau=T+1}^{T+k}\left(\frac{2+G_{s, \tau}^{\star}}{2-G_{s, \tau}^{\star}}\right) C_{s, T} .
$$

The aggregate emissions forecast at $T+k$ is then simply the sum of the state emission projections in that year: $\mathscr{C}_{T+k}^{\star}=\sum_{s} C_{s, T+k}^{\star}$.

To conserve space we consign the voluminous detailed parameter estimates to an online appendix. ${ }^{8}$ The fit of the model to our computed index numbers is generally good (R-sq. $\left.>0.5\right)$, with tests of the eigenvalues of the fitted system indicating stability (covariance stationarity and invertibility with an infinite-order vector moving-average representation) of our basic specification in 44 states. For the states failing the stability test (Kansas, Louisiana, Missouri, Nebraska, Pennsylvania, S. Carolina and Wyoming) we conducted systematic specification searches to uncover the

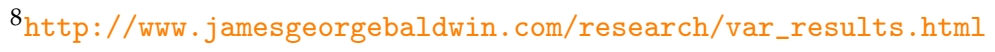


most parsimonious stable lag structure. This ended up being a lone second-order lag in the case of S. Carolina, and a second-order lag with the addition of a time trend for the rest. ${ }^{9}$

Based on these estimates we construct dynamic forecasts of the emissions precursors at the state level out to the year 2035. The resulting 30-year growth of the indexes of states' $\mathrm{CO}_{2}$ emissions and their precursors are shown in Figure 4. The contribution of $\mathrm{CO}_{2}$ intensity is generally small in magnitude and, with the exception of 13 states (most notably Arkansas and Oklahoma), tends to attenuate emissions growth. Energy intensity's overall impact is similar but more pronounced, while the contribution of change in industrial composition is about the same magnitude but more uniformly negative in its impact (except in Nebraska). The contributions of per capita income and population are both large and overwhelmingly positive, and are the dominant influences on the projected growth of states' $\mathrm{CO}_{2}$ emissions, which are forecast to more than double in Nevada and Virginia and more than triple in Georgia and New Hampshire. The implications of the aforementioned interstate divergence in income and population are apparent in the particularly rapid growth of emissions in the South (Georgia, Missouri, Virginia and the Carolinas) and the West (Colorado, Nevada, Utah and Washington).

The $95 \%$ confidence bounds of the projected annualized rates of growth of our precursors and the resulting emissions of $\mathrm{CO}_{2}$ at the state level are available as an online appendix ${ }^{10}$ The forecast confidence bounds are generally tight, with a tendency for the growth rates for population and per capita income effects to be bounded away from zero. This is less true for energy intensity, structural change, and particularly $\mathrm{CO}_{2}$ intensity, which does not exhibit statistically significant change in one third of the states. Forecast confidence intervals for the future trajectory of state, regional- and aggregate-level emissions were constructed using the delta method ${ }^{11}$ (see online

\footnotetext{
${ }^{9}$ Unit root tests on our state-level index number series indicated that the overwhelming majority of these variables are I(1). Mindful of the potential for spurious regression, we conducted cointegration rank tests of eq. (8). We then re-estimated our VARs as vector error-correction models. However, this yielded no improvements in stability, and although the resulting forecast means closely matched those from the VAR in levels, the standard errors were so large as to render the estimates unusable in constructing confidence intervals for future emissions. Following Lin and Tsay (1996) and Allen and Fildes (2005), we do not resort to running (8) on the first-differenced series. And since it has long been known that cointegration constraints may fail to improve long run forecasts in practical settings (Lin and Tsay, 1996; Hoffman and Rasche, 1996; Christoffersen and Diebold, 1998), we opt to retain the unconstrained VAR in levels as our preferred specification.

10 http://www. jamesgeorgebaldwin.com/research/forecastbounds.htm

${ }^{11}$ Nonstationarity in the state-level index numbers is a potential source of error in in the calculation of the standard errors from the VAR procedure, and thus the resulting forecast confidence intervals which our future research will seek to refine.
} 
Figure 4: 2008-35 \% Change in State-Level Indexes of $\mathrm{CO}_{2}$ Emissions and Precursors

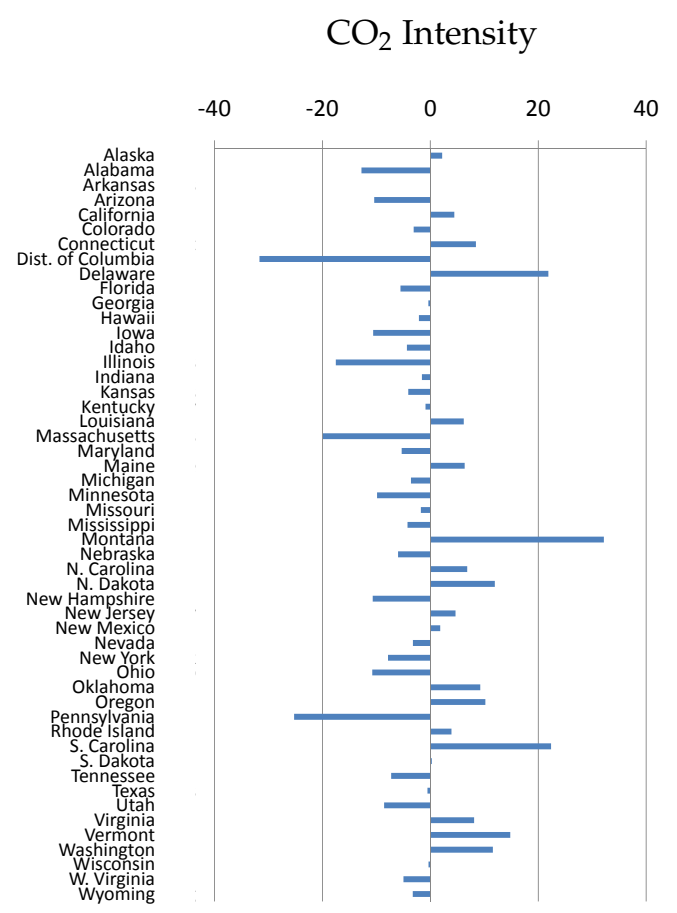

Per Capita Income
Energy Intensity

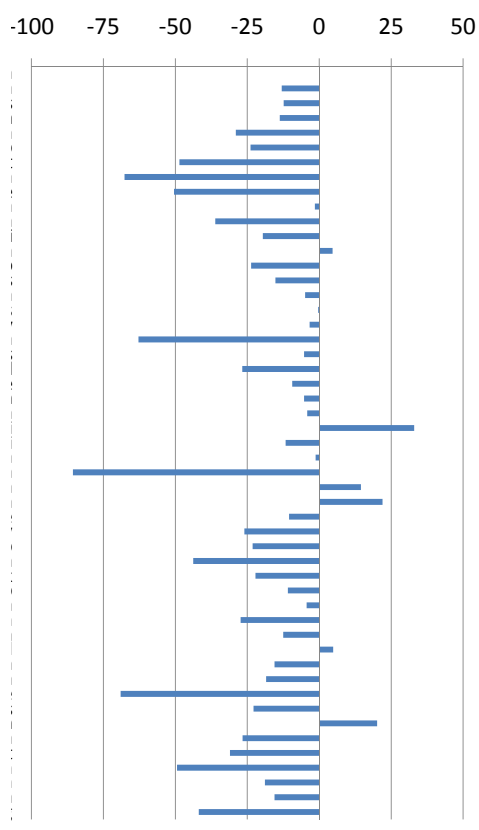

Population
Structural Change

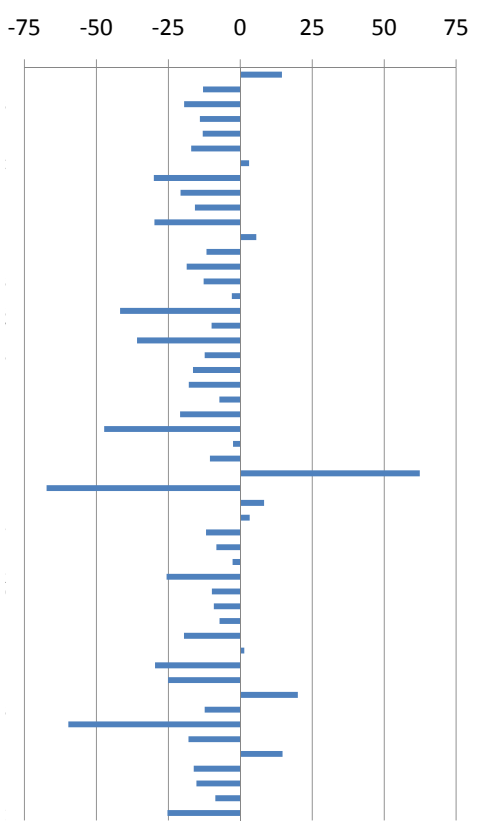

$\mathrm{CO}_{2}$ Emissions

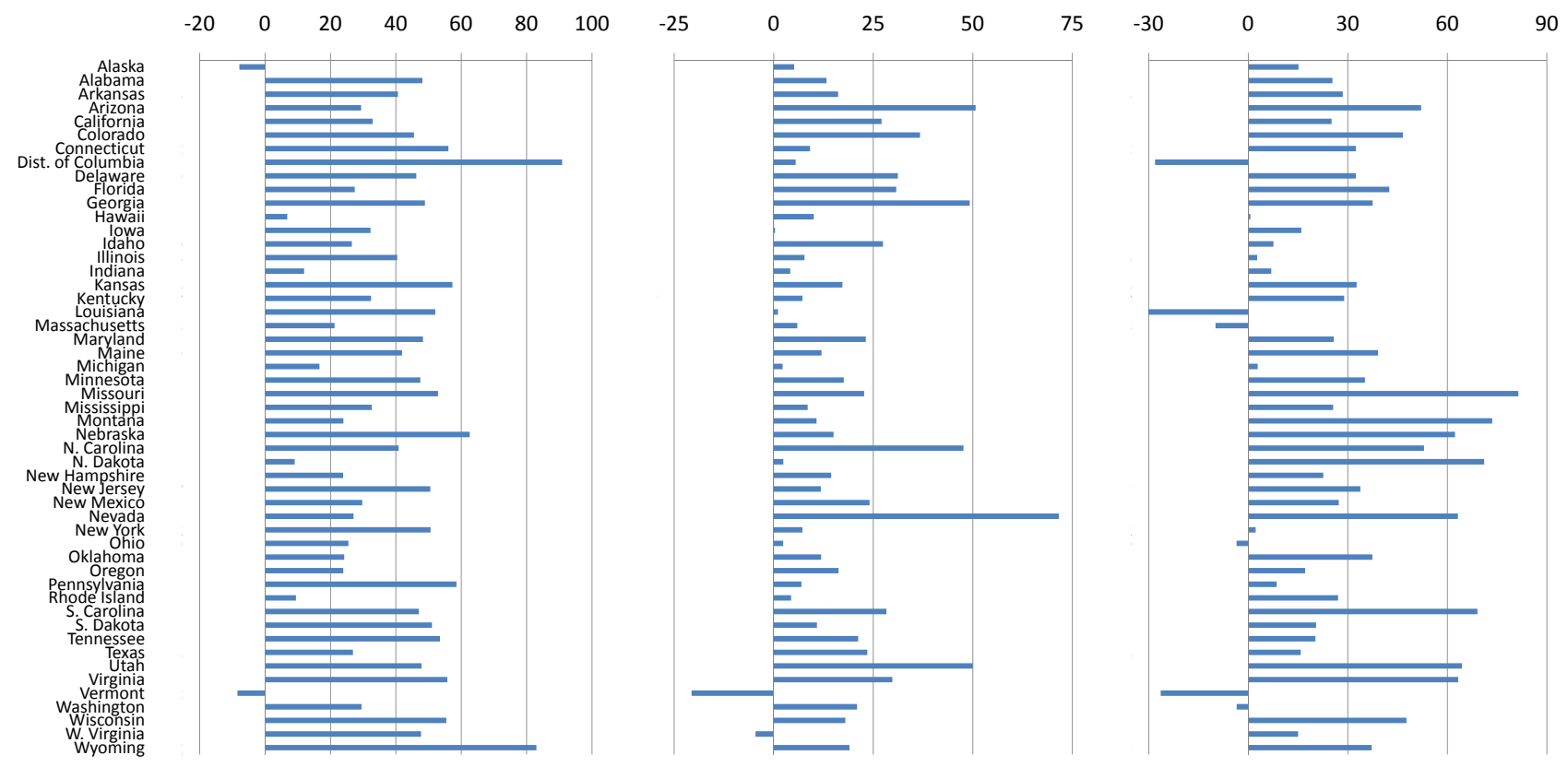


appendix ${ }^{12}$ ). The results for $\mathrm{CO}_{2}$ are equivocal in two fifths of the states, positive in 29 states and negative in four states.

The implication of the spatiotemporal evolution of $\mathrm{CO}_{2}$ precursors for the future trajectory of U.S. emissions is illustrated in Figure 5 and Figure 6. The implications of $\sigma$-divergence can be seen in panel A, where the 2008-2035 increase in the convexity of the schedule of rank-ordered state emissions suggests that under future climate mitigation policies, the interstate distribution of baseline emissions, $\mathrm{CO}_{2}$ abatement and associated primary economic burdens will be moderately more unequal compared to the present. Panel B shows that the estimated interrelationships among our five drivers suggest that aggregate emissions will continue to increase at average annual rates of $0.5-1.1 \%$, with the result that 2035 emissions will be $16-33 \%$ higher than their 2008 levels. Over the period 2009-2035 we project cumulative emissions of $182 \mathrm{GT}$ of $\mathrm{CO}_{2}$. The attenuating effects of energy intensity and structural change each reduce cumulative emissions by about 18 GT, with the result that cumulative $\mathrm{CO}_{2}$ would be some $22 \%$ higher had the influences of these precursors remained at 2008 levels.

By comparison, 2035 emissions in the 2010 Annual Energy Outlook (AEO) reference case forecast are $12 \%$ lower than our mean projection. This difference is unsurprising given that our data series do not capture the unprecedented declines in output and energy use associated with the severe recession of 2009-10. The fact that emissions in 2009 were 7\% lower than in 2008 (U.S. Energy Information Administration, 2010) makes us confident that updating our procedure as new data are released will bring the two sets of forecasts into closer agreement. But even so, EIA forecasts' tendency to overpredict energy intensity while underpredicting GDP (Auffhammer, 2007), and understate aggregate final energy (Fischer et al., 2009) suggest that the gap will not be entirely eliminated. Moreover, Figure 6 indicates that may be a persistent geographic component to such divergence. Although our confidence intervals overlap the AEO's forecast uncertainty regions over much of the country, we project substantially faster emissions growth in the East North Central, South Atlantic and East South Central regions. While the origins of this discrepancy are not clear, our own results nonetheless highlight the usefulness of our methodology in generating an empirically-grounded benchmark against which other long-run forecasts may be compared. The key policy implication is that, barring unforeseen major structural shifts in the US economy, over

\footnotetext{
12http://www. jamesgeorgebaldwin.com/research/CIcalculation.pdf
} 
Figure 5: Projected $\mathrm{CO}_{2}$ Emissions (MT)

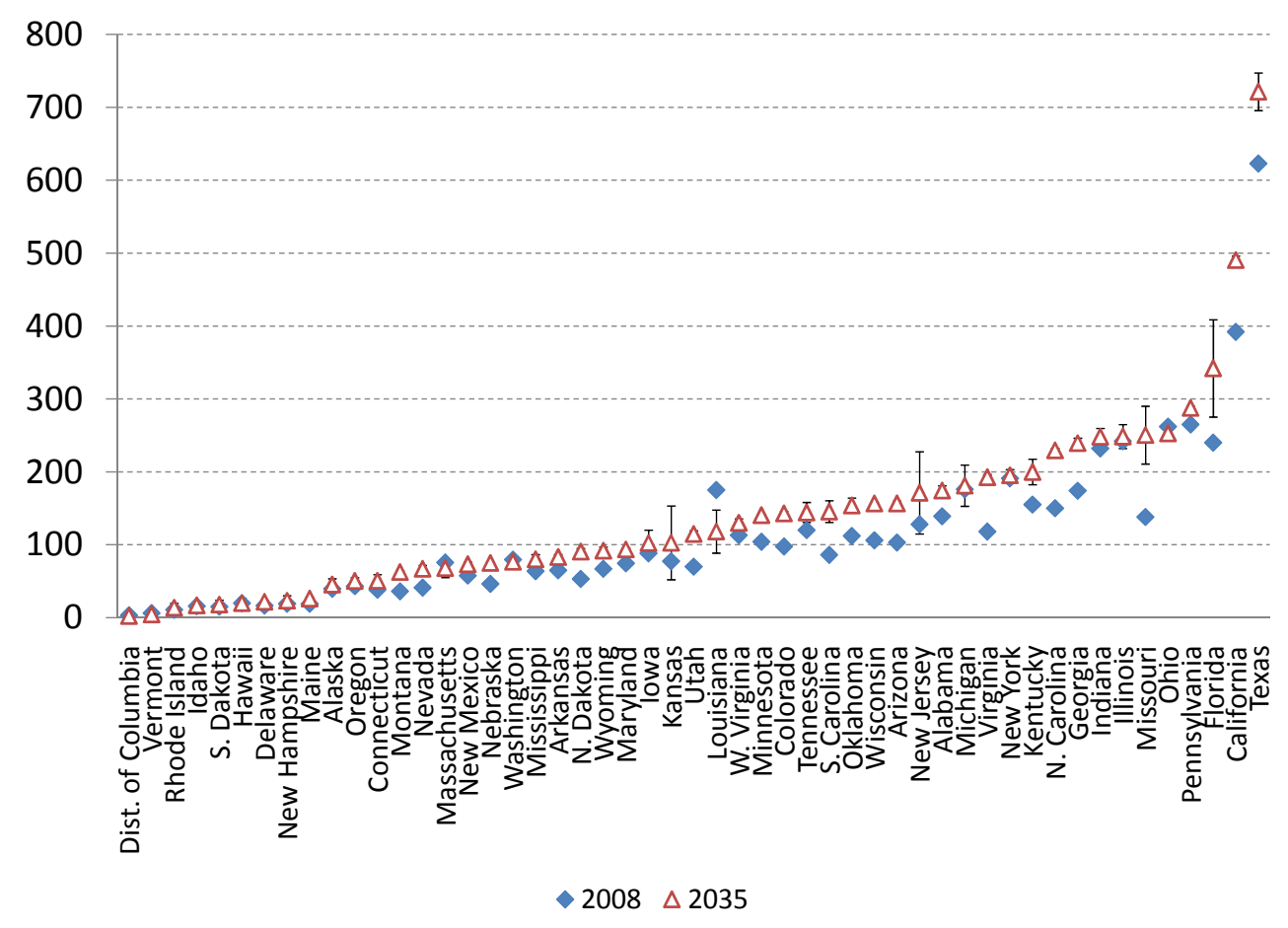

A. State Level

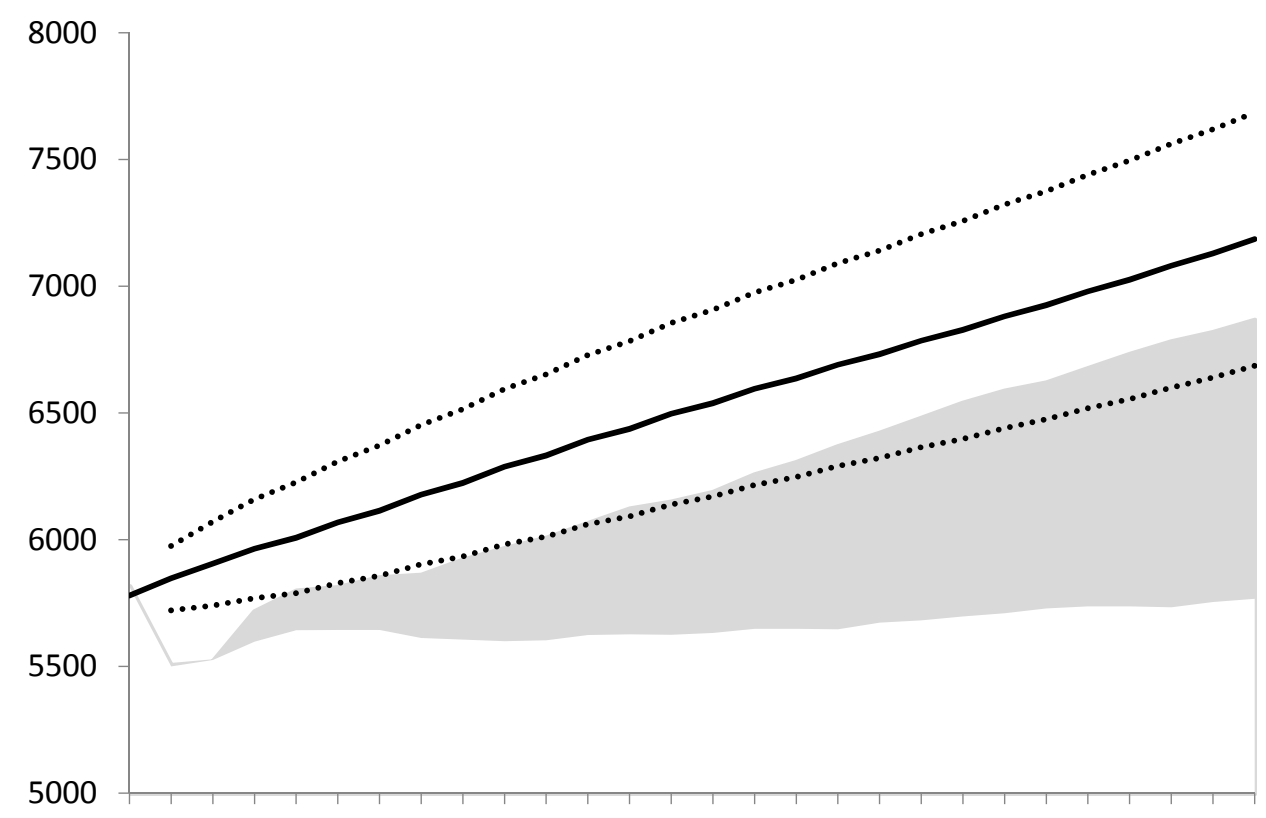

20082010201220142016201820202022202420262028203020322034

AEO 2010 Econ. Growth Uncertainty —VAR Projection $\quad \cdots . .95 \%$ VAR Confidence Interval

B. Aggregate Level 
the next quarter century aggregate emissions of carbon dioxide will continue to rise-and will likely do so more rapidly than official forecasts currently project. While all forecasts that make use of historical trends are subject to potential unexpected changes in technological, political or economic circumstance, the consequence of this baseline projection is an even greater challenge to state and federal policy makers in addressing climate change than is currently anticipated.

\section{Conclusion}

The evolution of carbon dioxide emitted by the US over the last 45 years suggests that reducing energy-related emissions is likely to be a great challenge. In this paper we have undertaken an index number decomposition analysis based on an extended Kaya-identity that apportions the growth of $\mathrm{CO}_{2}$ among five key driving forces. We find that at both the national and regional levels, growth of per capita income and especially population have been the major determinants of the increase in emissions, outstripping the principal mitigating influences of declining energy intensity and changing composition of output. The upshot is that emissions have largely stabilized in the northeast and grown slowly in the Midwest, while experiencing robust expansion in the south and west of the country. Despite considerable state-level heterogeneity in the trends in our precursors, the cumulative growth of states' emissions appear to be converging stochastically, driven by interfuel substitution, and, recently energy efficiency improvement and compositional shifts.

To assess the implications of these trends we developed a novel VAR forecasting methodology which employed our historical index number series as inputs to generate state and national emission projections to the year 2035. The results of our forecast indicate increasing dispersion in the interstate distribution of baseline emissions, suggesting that the abatement and economic burdens of any future emissions reduction policy is likely to be increasingly unequal. Owing to the effects of the 2009-10 recession, our aggregate emission projection is somewhat higher than the official AEO 2010 forecast. While the two sets of forecasts share many similarities at the level of U.S. regions, they tend to diverge in the south and central portions of the country. Finally, at both the regional and aggregate levels our forecast confidence intervals are comparable in magnitude to the economic growth uncertainty in the AEO. 


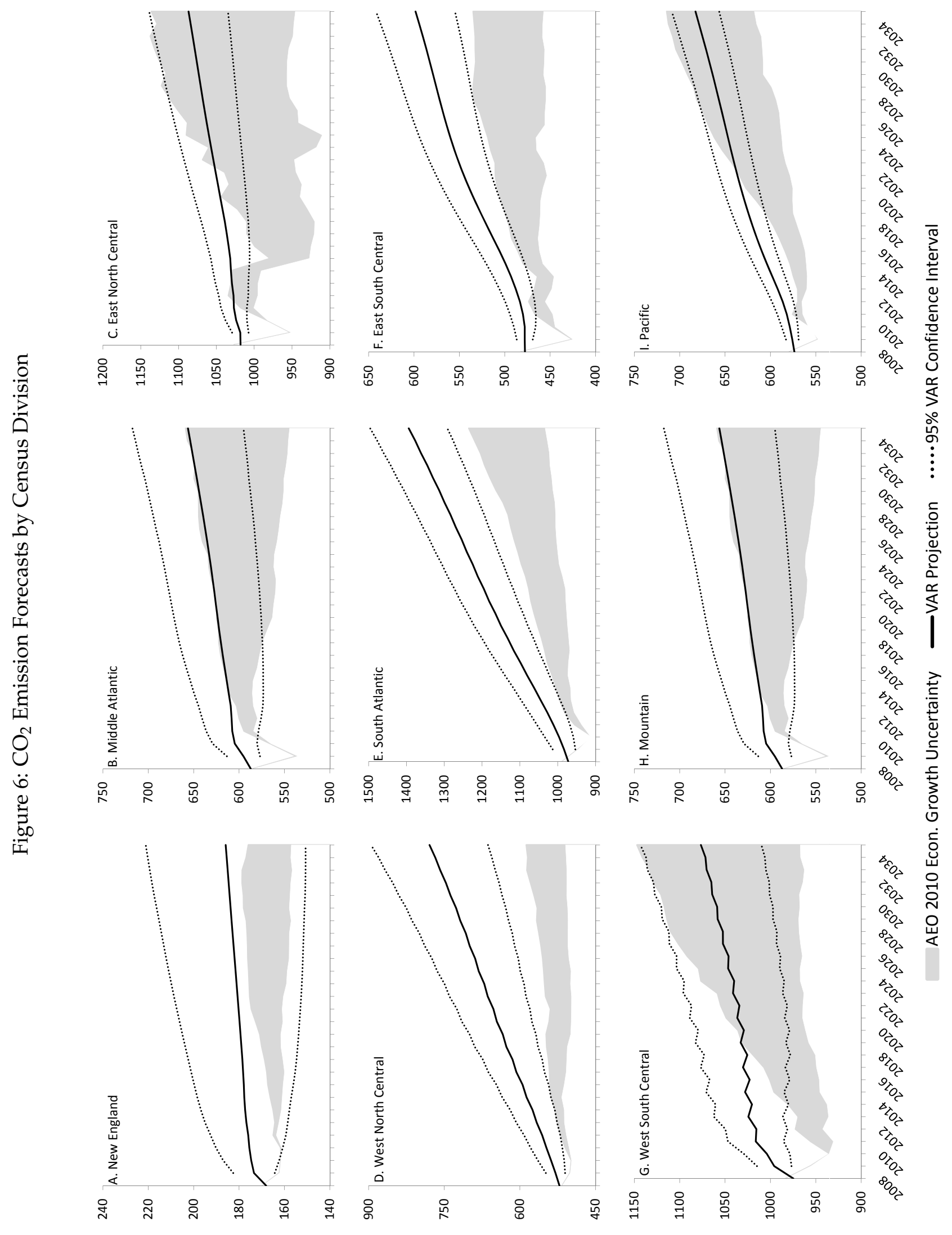




\section{References}

Aldy, J. (2007a). Energy and carbon dynamics at advanced stages of development: An analysis of the U.S. states, 1960-1999, The Energy Journal 28(1): 91-111.

Aldy, J. E. (2005). An environmental Kuznets curve analysis of U.S. state-level carbon dioxide emissions, The Journal of Environment and Development 14(1): 48-72.

Aldy, J. E. (2007b). Divergence in state-level per capita carbon dioxide emissions, Land Economics 83(3): 353-369.

Allen, P. G. and Fildes, R. (2005). Levels, differences and ECMs: Principles for improved econometric forecasting, Oxford Bulletin of Economics and Statistics 67: 881-904.

Ang, B. (2002). Decomposition methodology in energy demand and environmental analysis, in J. van den Bergh (ed.), Handbook of Environmental and Resource Economics, Edward Elgar, Northampton, MA, pp. 1131-1139.

Ang, B. (2005). The LMDI approach to decomposition analysis: a practical guide, Energy Policy 33(7): 867-871.

Ang, B. and Liu, F. (2001). A new energy decomposition method: perfect in decomposition and consistent in aggregation, Energy 26(6): 537-547.

Ang, B., Liu, F. and Chung, H. (2004). A generalized Fisher index approach to energy decomposition analysis, Energy Economics 26(5): 757-763.

Ang, B. and Liu, N. (2007). Negative-value problems of the logarithmic mean Divisia index decomposition approach, Energy Policy 35(1): 739-742.

Ang, B. and Zhang, F. (2000). A survey of index decomposition analysis in energy and environmental studies, Energy 25(12): 1149-1176.

Auffhammer, M. (2007). The rationality of EIA forecasts under symmetric and asymmetric loss, Resource and Energy Economics 29(2): 102 - 121. 
Auffhammer, M. and Steinhauser, R. (2007). The future trajectory of $\mathrm{US} \mathrm{CO}_{2}$ emissions: The role of state vs. aggregate information, Journal of Regional Science 47(1): 47-62.

Auffhammer, M. and Steinhauser, R. (2010). Forecasting the path of U.S. $\mathrm{CO}_{2}$ emissions using state-level information, Review of Economics and Statistics in press.

Barro, R. J. and Sala-i Martin, X. (1992). Convergence, Journal of Political Economy 100(2): 223-251.

Blanchard, O. J. and Gali, J. (2007). The macroeconomic effects of oil shocks: Why are the 2000s so different from the 1970s?, NBER Working Papers 13368, National Bureau of Economic Research.

Bohi, D. R. (1991). On the macroeconomic effects of energy price shocks, Resources and Energy 13(2): 145-162.

Boyd, G. A. and Roop, J. M. (2004). A note on the Fisher ideal index decomposition for structural change in energy intensity, The Energy Journal 25(1): 87-101.

Burbidge, J. and Harrison, A. (1984). Testing for the effects of oil-price rises using vector autoregressions, International Economic Review 25(2): 459-84.

Byrne, J., Hughes, K., Rickerson, W. and Kurdgelashvili, L. (2007). American policy conflict in the greenhouse: Divergent trends in federal, regional, state, and local green energy and climate change policy, Energy Policy 35(9): 4555 - 4573.

Christoffersen, P. and Diebold, F. (1998). Cointegration and long-horizon forecasting, Journal of Business and Economic Statistics 16: 450-458.

Diakoulaki, D. and Mandaraka, M. (2007). Decomposition analysis for assessing the progress in decoupling industrial growth from $\mathrm{CO}_{2}$ emissions in the EU manufacturing sector, Energy Economics 29(4): 636-664.

Ebohon, J. O. and Ikeme, A. J. (2006). Decomposition analysis of $\mathrm{CO}_{2}$ emission intensity between oil-producing and non-oil-producing Sub-Saharan African countries, Energy Policy 34(18): 3599_ 3611.

Edelstein, P. and Kilian, L. (2009). How sensitive are consumer expenditures to retail energy prices?, Journal of Monetary Economics 56(6): 766 - 779. 
EIA (2012). Official energy statistics from the U.S. government, http:/ / www.eia.gov.

EPA (2012). State and local climate and energy program, http://www.epa.gov/statelocalclimate/state/index.html.

Fischer, C., Herrnstadt, E. and Morgenstern, R. (2009). Understanding errors in EIA projections of energy demand, Resource and Energy Economics 31(3): 198 - 209.

Grainger, C. and Kolstad, C. D. (2009). Who pays a price on carbon?, Working paper No. 15239, National Bureau of Economic Research.

Hamilton, J. D. (1983). Oil and the macroeconomy since world war ii, Journal of Political Economy 91(2): pp. 228-248.

Hamilton, J. D. (2003). What is an oil shock?, Journal of Econometrics 113(2): 363-398.

Hassett, K. A., Mathur, A. and Metcalf, G. E. (2009). The incidence of a U.S. carbon tax: A lifetime and regional analysis, Energy Journal 30: 155-177.

Hoffman, D. L. and Rasche, R. H. (1996). Co-integration constraint and forecasting: An empirical examination, Journal of Applied Econometrics 11(5): 495-517.

Im, K. S., Pesaran, M. H. and Shin, Y. (2003). Testing for unit roots in heterogeneous panels, Journal of Econometrics 115(1): 53-74.

Jimenez-Rodriguez, R. and Sanchez, M. (2005). Oil price shocks and real gdp growth: empirical evidence for some oecd countries, Applied Economics 37(2): 201-228.

Kawase, R., Matsuoka, Y. and Fujino, J. (2006). Decomposition analysis of $\mathrm{CO}_{2}$ emissions in longterm climate stabilization scenarios, Energy Policy 34(15): 2113-2122.

Kaya, Y. (1990). Impact of carbon dioxide emission control on GNP growth: interpretation of proposed scenarios., Paper presented at the IPCC Energy and Industry Subgroup, Response Strategies Working Group, Paris, France.

Lee, K. and Oh, W. (2006). Analysis of $\mathrm{CO}_{2}$ emissions in APEC countries: A time-series and crosssectional decomposition using the log mean Divisia method, Energy Policy 34(17): 2779-2787. 
Lin, J.-L. and Tsay, R. S. (1996). Co-integration constraint and forecasting: An empirical examination, Journal of Applied Econometrics 11(5): 519-538.

List, J. A. (1999). Have air pollutant emissions converged among U.S. regions? Evidence from unit root tests, Southern Economic Journal 66(1): 144-145.

Lu, I., Lin, S. J. and Lewis, C. (2007). Decomposition and decoupling effects of carbon dioxide emission from highway transportation in Taiwan, Germany, Japan and South Korea, Energy Policy 35(6): 3226-3235.

Lutsey, N. and Sperling, D. (2008). America's bottom-up climate change mitigation policy, Energy Policy 36(2): 673-685.

Metcalf, G. E. (2008). An empirical analysis of energy intensity and its determinants at the state level, Energy Journal 29(3): 1-26.

Mork, K. A. (1989). Oil and the macroeconomy when prices go up and down: An extension of hamilton's results, Journal of Political Economy 97(3): pp. 740-744.

Mork, K. A., Olsen, O. and Mysen, H. T. (1994). Macroeconomic responses to oil price increases and decreases in seven oecd countries, The Energy Journal Volume15(Number 4): 19-36.

Rabe, B. G. (2008). States on steroids: The intergovernmental odyssey of american climate policy, Review of Policy Research 25(2): 105-128.

Raupach, M. R., Marland, G., Ciais, P., Le Quere, C., Canadell, J. G., Klepper, G. and Field, C. B. (2007). Global and regional drivers of accelerating $\mathrm{CO}_{2}$ emissions, Proceedings of the National Academy of Sciences 104(24): 10288-10293.

Strazicich, M. and List, J. (2003). Are $\mathrm{CO}_{2}$ emission levels converging among industrial countries?, Environmental and Resource Economics 24(3): 263-271.

Sue Wing, I. (2008). Explaining the declining energy intensity of the U.S. economy, Resource and Energy Economics 30(1): 21-49.

Sue Wing, I. (2010). The regional incidence of a national greenhouse gas emission limit: Title VII of the American Clean Energy and Security Act, Working paper, Boston University. 
U.S. Energy Information Administration (2010). U.S. carbon dioxide emissions in 2009: A retrospective review, http://www.eia.doe.gov/oiaf/environment/emissions/carbon/index. html.

Yang, C. and Schneider, S. (1998). Global carbon dioxide emissions scenarios: Sensitivity to social and technological factors in three regions, Mitigation and Adaptation Strategies for Global Change 2(4): 373-404. 